\title{
Estimating and Modeling the Effects of Grass Growth on Surface Runoff through a Rainfall Simulator on Field Plots
}

\author{
Nicola Montaldo, Matteo Curreli, Roberto Corona, and Andrea Saba \\ Dipartimento di Ingegneria Civile, Ambientale e Architettura, Università di Cagliari, Cagliari, Italy \\ JOHN D. ALBERTSON \\ Department of Civil and Environmental Engineering, Cornell University, Ithaca, New York
}

(Manuscript received 20 Februrary 2020, in final form 25 April 2020)

\begin{abstract}
Seasonal changes in grass cover impact the generation of surface runoff due to the effects of grass roots on soil hydrologic properties and processes (i.e., infiltration). Using a rainfall simulator in a grass field site, we broadly investigated the influence of different initial conditions of soil moisture and grass growth stages on rainfall-runoff transformations. To parameterize the stages of grass growth, we used the height of the vegetation $h_{\mathrm{veg}}$, which is related to the leaf area index. Surprisingly, typical characteristics of runoff formation (peak flow and time to peak flow) were conditioned mainly by $h_{\text {veg. }}$ The runoff coefficient decreased about $40 \%$ when grass reached its maximum growth and was inversely and significantly related to the height of grass in general. Using the rainfall simulator experiments, we estimated the saturated soil hydraulic conductivity $k_{s}$, a key parameter of infiltration models. We found strong relationships between $k_{s}$ and $h_{\mathrm{veg}}$ when the Philip infiltration model was used, and we proposed a linear relationship between $k_{s}$ and $h_{\mathrm{veg}}$, making $k_{s}$ vary in time with grass growth (i.e., $h_{\mathrm{veg}}$ ). We compared predictions of hydrologic models at plot scale using $k_{s}$ varying with grass growth with predictions using a constant $k_{s}$, as hydrological models commonly assume. Neglecting $k_{s}$ variability with grass growth can lead to errors up to $100 \%$ in surface runoff predictions at an event time scale and up to $87 \%$ at a monthly time scale. Ecohydrological models for runoff predictions should take into account the influence of grass growth dynamics on soil infiltration parameters.
\end{abstract}

\section{Introduction}

Grass species are common to all continents except Antarctica, and grasslands cover approximately $26 \%$ of terrestrial area globally (Foley et al. 2011; Obermeier et al. 2016). Seasonal changes in grass cover are known to impact the interception of precipitation (Burgy and Pomeroy 1958; McMillan and Burgy 1960; Crouse et al. 1966), but they may also impact the generation of surface runoff due to the effects of grass on soil hydrological properties (Gutierrez and Hernandez 1996). Indeed, vegetation cover not only intercepts raindrops but also prevents surface sealing, and grass root holes can generate macropores and interpedal soil space that increase the local conductivity of water and allow for the escape of air (Dunne et al. 1991; Angers and Caron 1998). Vegetation growth contributes to the formation of pores by roots that exert compressive and shear stresses on

Corresponding author: Nicola Montaldo,nmontaldo@unica.it soil, and roots may enhance soil permeability and infiltration capacity by developing macropore systems that offer preferential directions for water infiltration (Angers and Caron 1998). The effect of grass growth on soil infiltration and, therefore, on surface runoff, has been incompletely quantified to date.

Field-based evaluations of rainfall-runoff transformations are the first step to quantify this effect. Rainfall simulators are the state-of-the-art method (Foster et al. 2000; Rulli et al. 2006; Leitinger et al. 2010; Wilson et al. 2014). Only a few rainfall simulator-based efforts have investigated the effect of grass seasonality on surface runoff. While Cerdà (1996) and Leitinger et al. (2010) detected no changes in surface runoff with grass growth due to the low simulated surface runoff in the predominantly sandy soils of their experiments, Gutierrez and Hernandez (1996), as expected, observed less surface runoff with more-grown grass using a drip-type rainfall simulator in silty clay loam soils of New Mexico (United States) semiarid rangeland. However, Gutierrez and 
Hernandez (1996) also used a small rainfall simulator $\left(1-\mathrm{m}^{2}\right.$ area $)$ and low rain intensity $\left(13.75 \mathrm{~mm} \mathrm{~h}^{-1}\right)$ on a patchy grassland, so further investigations are needed with larger, more representative rainfall simulators (Sharpley and Keinman 2003; Wilson et al. 2014; Mayerhofer et al. 2017), in which plot sizes should be $>10-50 \mathrm{~m}^{2}$ (Schindler Wildhaber et al. 2012) in order to reduce side effects and increase the accuracy of runoff coefficient estimates, and with higher rainfall intensities on more uniform grass fields. In this regard, we propose to use the Wilson et al. (2014) rainfall simulator with larger area $\left(\sim 16 \mathrm{~m}^{2}\right)$ and higher rainfall intensity (up to $62 \mathrm{~mm} \mathrm{~h}^{-1}$ ) to definitively evaluate the effects of grass growth on surface runoff.

The effects of grass growth on surface runoff generation may have implications for hydrologic modeling, since grass growth changes soil's hydrological properties and, therefore, soil model parameters. Soil parameters of common infiltration models (e.g., Philip 1957; Horton 1933, 1939; Green and Ampt 1911) are usually maintained constant over a year (Bormann and Klaassen 2008). Ecohydrologic models, which couple hydrologic and vegetation dynamic models to account mainly for the dynamic effects of vegetation on evapotranspiration and rainfall interception, have been developed in recent decades (e.g., Nouvellon et al. 2000; Arora 2003; Montaldo et al. 2005, 2008), but these have not yet considered the dynamic effects of vegetation on infiltration modeling. Infiltration model parameters are related to hydrological properties of soil, which are potentially affected by seasonal changes in vegetation due to the effects of vegetation growth, more specifically root growth and throughfall dispersion, on soil porosity and permeability. Infiltration parameters may change across the year following the seasonality of grass growth. Among infiltration model parameters, saturated hydraulic conductivity $k_{s}$ is the widely recognized key parameter (Kabat et al. 1997; Albertson and Kiely 2001; Montaldo et al. 2003), so we focus our analysis on that soil parameter.

While several field experiments investigated the effects of grass cover on infiltration for plots with the same soil type but with different grass cover (Dadkhah and Gifford 1980; Dunne et al. 1991; Kato et al. 2009; Podwojewski et al. 2011), and Dunne et al. (2011) did not find any correlation between infiltration and the increasing grass on a short period ( 35 days) in southern Kenya, no evaluation of the effect of seasonal grass cover changes on soil model parameters at the same site has ever been made using rainfall simulator-based field experiments. A few, contrasting field experiments have investigated the sensitivity of $k_{s}$ to vegetation growth using the constant-head method for infiltration. Bormann and Klaassen (2008), as expected, estimated that soil bulk density decreases during the plant-growth season in several fields (two with grass) of North Germany and, accordingly, that $k_{s}$ increases " $d u e$ to an increasing soil aggregation and an increasing density of continuous macropores" (Bormann and Klaassen 2008). By contrast, $\mathrm{Hu}$ et al. (2012) confirmed that $k_{s}$ varies seasonally in a bunge needlegrass Chinese transect, but the highest values were obtained in March (at the start of the growing season), decreasing until October, due to the high rainfall contribution between June and October with soils undergoing frequent wetting and drying processes to produce increasing surface soil sealing by raindrops. Recently, Gadi et al. (2017), using the constant-head method, investigated the spatial and temporal variability of the hydraulic conductivity in a mixed grass area, and they estimated an increase of up to an order of magnitude in the hydraulic conductivity when vegetation density increased during one growing season (from January to June). However, Gadi et al. (2017) did not investigate hydraulic conductivity behavior in different seasons and years and did not use a rainfall simulator. Indeed, compared to the constanthead method for infiltration, rainfall simulators estimate rainfall-runoff transformations more fully and realistically at the field plot scale. Wilson et al. (2014) showed it is possible to use the results of rainfall simulator experiments to estimate $k_{s}$ in the Philip infiltration model. Starting from Wilson et al.'s (2014) approach, we evaluated the impact of grass growth on $k_{s}$, repeating rainfall simulator experiments at different stages of grass growth, estimating $k_{s}$ for each. Note that vegetation growth may also impact hydraulic roughness parameters for runoff propagation, but this study is limited to plot-scale effects rather than basin-scale hydrological processes.

This work addresses the following objectives: 1) to quantify the effect of grass growth on surface runoff using a rainfall simulator to estimate rainfall-runoff transformation; 2) to evaluate the effects of grass growth on a key parameter in the infiltration model, $k_{s}$, and estimate its variability with grass growth; and 3) to identify the relevance of using $k_{s}$ that varies with grass growth in surface runoff predictions of hydrologic models at plot spatial scale and at the event and monthly time scales, which are typical time scales for the design of flood protection and water resources planning.

To this end, we used the Wilson et al. (2014) rainfall simulator on a grass field in the center of Sardinia (Italy) during different stages of the grass life cycle. Corona et al. (2013) and Wilson et al. (2014) demonstrated that the rainfall simulator system generates highly accurate 


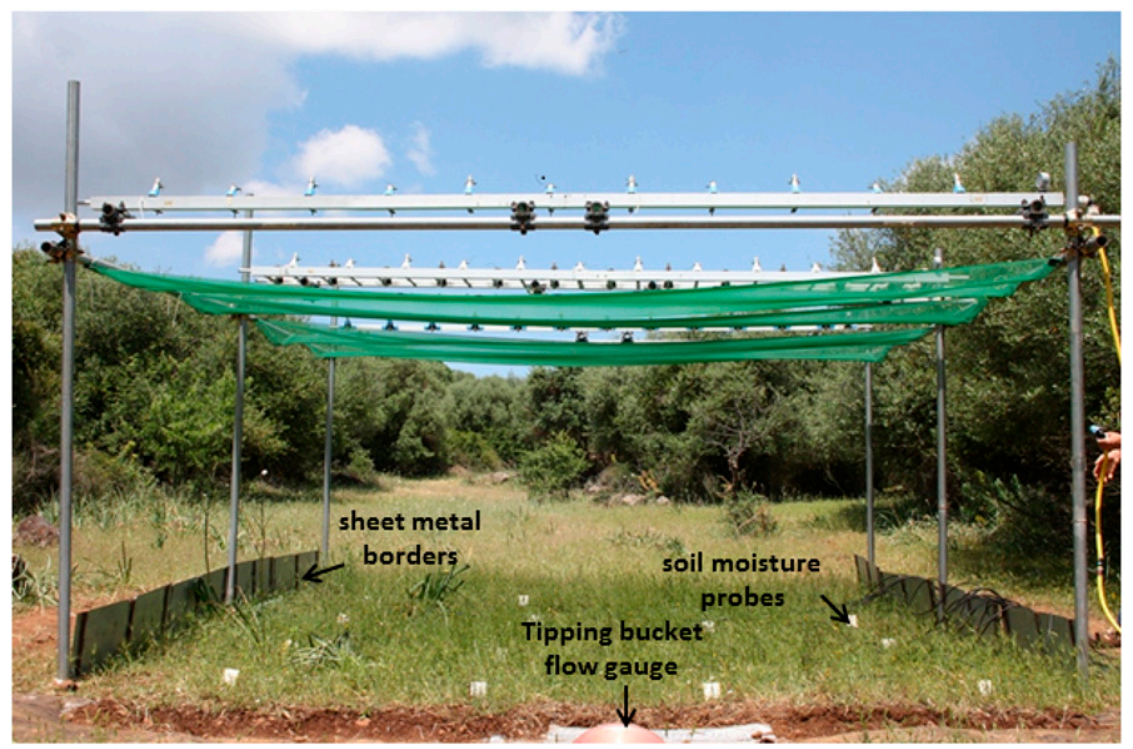

FIG. 1. The rainfall simulator experiment at the Sardinian experimental field site (dated 29 May 2012).

rainfall fields (area $\sim 16 \mathrm{~m}^{2}$ ). Using the results of the rainfall simulator experiments for several conditions of grass growth, we investigated the effects of grass growth on runoff generation. We estimated $k_{s}$ following the Wilson et al. (2014) approach using the common Philip infiltration model, and then we investigated how grass growth seasonality affected $k_{s}$. Finally, we evaluated the relevance of using variable $k_{s}$ as a function of grass growth (in contrast with time-invariant $k_{s}$ ) for predicting surface runoff at several time scales. For this we also used the Montaldo et al. (2008) ecohydrologic model, which had already been calibrated at the Sardinian field site (i.e., local scale) for soil moisture predictions in a multiannual period.

\section{Methods}

First, we describe the rainfall simulator, the experiments, and the field site. Then, we illustrate the Philip infiltration model used to model the results of the rainfall simulator experiment and outline the approach to estimating $k_{s}$. Finally, we describe the ecohydrologic model of Montaldo et al. (2008), which uses the Philip model for infiltration estimates.

\section{a. The rainfall simulator}

The rainfall simulator comprised several parts: nozzle lines, nozzle supports, a structural frame, and a water delivery system (Wilson et al. 2014; Fig. 1). The four independently operated nozzle lines have either 11 or 12 nozzle assemblies (46 total). Each nozzle assembly consists of a pressure-washing nozzle with a $0.5-\mathrm{mm}$ opening, threaded hex connector, and threaded hose barb. Each line totals $4.2 \mathrm{~m}$ long and has a plugged length of pipe at one end and a $0-600$-mbar pressure gauge and elbow at the other end that connects to the water delivery system. The nozzle assemblies are supported by L-shaped pieces of metal mounted to a stiff metal frame. The nozzles point upward at alternating angles of $48^{\circ}$ and $54^{\circ}$ from horizontal; the drops then fall from approximately $3 \mathrm{~m}$ above the surface. The structural frame comprises six 2-m vertical beams, three 4-m horizontal beams to which the nozzles are mounted, and two 4-m horizontal beams to complete the frame, for overall measurements of $4 \mathrm{~m} \times 4 \mathrm{~m} \times 2 \mathrm{~m}$, and the irrigated area was $15.12 \mathrm{~m}^{2}$. Additional details on the rainfall simulator may be found in Corona et al. (2013) and Wilson et al. (2014). The spatial uniformity of the generated rainfall fields has been tested successfully (coefficient of uniformity of $76 \%$, Wilson et al. 2014), and the rainfall simulator's efficiency in generating natural distributions of drop size has been thoroughly tested through extensive disdrometer measurements (drop diameter in $300 \mathrm{~s}$ ranged $0.2-3.3 \mathrm{~mm}$ with distribution frequency peak at $1 \mathrm{~mm}$, and impact velocity ranged 1-5 $\mathrm{m} \mathrm{s}^{-1}$; Corona et al. 2013).

\section{b. Field site and experimental setup}

The experiments were performed at a field site in Orroli, Italy ( $\left.39^{\circ} 41^{\prime} 12.57^{\prime \prime} \mathrm{N}, 9^{\circ} 16^{\prime} 30.34^{\prime \prime} \mathrm{E}, 560 \mathrm{~m} \mathrm{MSL}\right)$, on the island of Sardinia (Montaldo et al. 2008), from July 2010 to May 2012 (Table 1 ). The climate at the site 
TABLE 1. Date, height of vegetation $h_{\mathrm{veg}}$, duration of the experiment $T$, initial spatial mean soil moisture content $\overline{\theta_{i}}$, peak flow $q_{p}$, and time to peak flow $t_{p}$ of the rainfall simulator field experiments.

\begin{tabular}{lcrccc}
\hline \hline \multicolumn{1}{c}{ Date } & $h_{\text {veg }}(\mathrm{cm})$ & $T(\mathrm{~min})$ & $\overline{\theta_{i}}(-)$ & $q_{p}\left(\mathrm{~mm} \mathrm{~h}^{-1}\right)$ & $t_{p}(\mathrm{~min})$ \\
\hline 29 Jul 2010 & 6 & 35 & 0.45 & 43 & 25 \\
2 Aug 2010 & 6 & 89 & 0.38 & 42 & 82 \\
25 Jun 2011 & 25 & 123 & 0.37 & 30 & 95 \\
23 Dec 2011 & 1 & 58 & 0.40 & 50 & 10 \\
25 Jan 2012 & 1 & 58 & 0.33 & 45 & 25 \\
10 May 2012 & 15 & 127 & 0.13 & 34 & 110 \\
11 May 2012 & 15 & 70 & 0.39 & 36 & 67 \\
29 May 2012 & 16 & 145 & 0.20 & 38 & 91 \\
\hline
\end{tabular}

is maritime Mediterranean, with mean annual precipitation (1922-2007) of $643 \mathrm{~mm}$ and mean historical monthly precipitation ranging from $11 \mathrm{~mm}$ in July to $102 \mathrm{~mm}$ in December. Mean annual air temperature is $14.6^{\circ} \mathrm{C}$, and the mean historical monthly temperature ranges from a minimum of $7.1^{\circ} \mathrm{C}$ in January to a maximum of $23.7^{\circ} \mathrm{C}$ in July.

Grasses (Bellium bellidioides, Bellis perennis, Avena fatua, Hordeum murinum) reach their maximum growth at the end of spring; grass then dies, yellowing at the end of summer (the driest season). The grass cover area was uniform and densely covered, approximately $95 \%$ (Wilson et al. 2014), and changes of spatial grass coverage were negligible through the seasons. To parameterize the stages of grass growth, at the field scale we used the height of the vegetation $h_{\mathrm{veg}}$, which is an ecological metric that evolves dynamically with vegetation structure (Yuan et al. 2013; Fatichi et al. 2012) and is closely related to the leaf area index (LAI; Gao et al. 2013; Yuan et al. 2013), a key vegetation parameter of land surface models (Noilhan and Planton 1989; Nouvellon et al. 2000; Montaldo et al. 2005). The grass growth was slow. Indeed, $h_{\text {veg }}$ typically was $\sim 1 \mathrm{~cm}$ in the month of December, and maintained this height during winter. Then in spring the favorable radiation, temperature, and soil moisture conditions led to a fast growth of all grass species that reached the maximum high of $\sim 25 \mathrm{~cm}$ in late June. At the end of summer, aboveground herbage yellowed, and root activity started to reduce, as common in Mediterranean species (Volaire and Norton 2006). Hence, on the observation days, $h_{\mathrm{veg}}$ ranged between 1 (fall) and $25 \mathrm{~cm}$ (at end of spring; Table 1). Parameter $h_{\text {veg }}$ was related to LAI through a field-measured relationship $\left(h_{\mathrm{veg}}=\right.$ $\left.6.225 \mathrm{LAI}^{2}+7.572 \mathrm{LAI} ; R^{2}=0.99, p<0.01\right)$ at the Orroli site. LAI was measured indirectly through a ceptometer (AccuPAR model PAR-80, Decagon Devices Inc., Pullman, Washington, United States; Montaldo et al. 2008).
The land gently slopes approximately $4.6^{\circ}$. The soil is $17 \mathrm{~cm}$ in depth (coincident with the root zone depth) above a fractured basalt. The soil is a silt loam, with mean bulk density of $1.48 \mathrm{~g} \mathrm{~cm}^{-3}$ in the first $10 \mathrm{~cm}$ (standard deviation, SD, of $0.06 \mathrm{~g} \mathrm{~cm}^{-3}$ ) and $1.66 \mathrm{~g} \mathrm{~cm}^{-3}$ in the 10-17-cm soil layer (SD of $0.16 \mathrm{~g} \mathrm{~cm}^{-3}$ ), and with a porosity of $53 \%$ (Montaldo et al. 2008). A value of $5 \times 10^{-6} \mathrm{~m} \mathrm{~s}^{-1}$ of $k_{s}$ was estimated in May 2004 using a 2800KI Guelph permeameter (Soilmoisture Equipment Corp.). Grass root density was $0.5-1.0 \mathrm{~kg} \mathrm{~m}^{-3}$. Along the perimeter of the rainfall simulator, a thin sheet metal was inserted approximately $10 \mathrm{~cm}$ into the ground to help prevent lateral flow of water across the plot boundaries (Fig. 1; Wilson et al. 2014). A total of 15 time-domain reflectometry probes (Campbell Scientific CS616) were used to monitor soil moisture $\theta$. The probes measured the top $15 \mathrm{~cm}$ of the soil in a regular grid of $1 \mathrm{~m} \times 1 \mathrm{~m}$ (Fig. 1). Data were recorded by a datalogger (Campbell Scientific CR 3000). The spatial mean soil moisture $\bar{\theta}$ was estimated at each time step. To check the amount of water delivered to the plot, three simple $10 \mathrm{~cm}$ rain gauges were also placed inside the irrigated area. Runoff from the plot was collected using a tippingbucket flow gauge, based on the design of Chow (1976). In this gauge design, a metal box open on the sides supports two Plexiglas buckets that each hold approximately $2 \mathrm{~L}$. Water flows into the bucket from a hose attached to the back of the structure. The datalogger recorded the time of the pulse created by each tip. To collect surface runoff, a shallow trench was dug at the bottom edge of the plot, and a plastic ledge was inserted into the ground just below the surface to direct the water onto plastic sheeting. From there, the water flowed by gravity into a tube that was connected to the tippingbucket flow gauge (Wilson et al. 2014).

Eight experiments were performed during the 2010-12 observation period (Table 1) to investigate grass growth stages. Rain intensity $i$ was on average $61.6 \mathrm{~mm} \mathrm{~h}^{-1}$ with low variability (standard deviation of $0.8 \mathrm{~mm} \mathrm{~h}^{-1}$ ); the return period of this rain intensity is about 60 years for the Sardinia island (varying geographically from 20 to 300 years across Sardinian rain gauge stations). The rainfall intensity was chosen to ensure runoff production. The initial spatial mean soil moisture content $\overline{\theta_{i}}$ was different in each experiment, and the duration of the experiments $T$ also varied, as each experiment terminated upon reaching peak $q_{p}$ and relatively constant discharge $q$ (Corona et al. 2013; Wilson et al. 2014). The test conditions $\left(h_{\mathrm{veg}}, \overline{\theta_{i}}\right.$, and $T$ values) are in Table 1 . For each experiment, we also estimated $q_{p}$ and the time to peak $t_{p}$ (Table 1). Using $q_{p}$, we estimated the peak runoff coefficient $\left(\phi=q_{p} / i\right)$ for each rainfall simulation experiment (Fig. 2). 


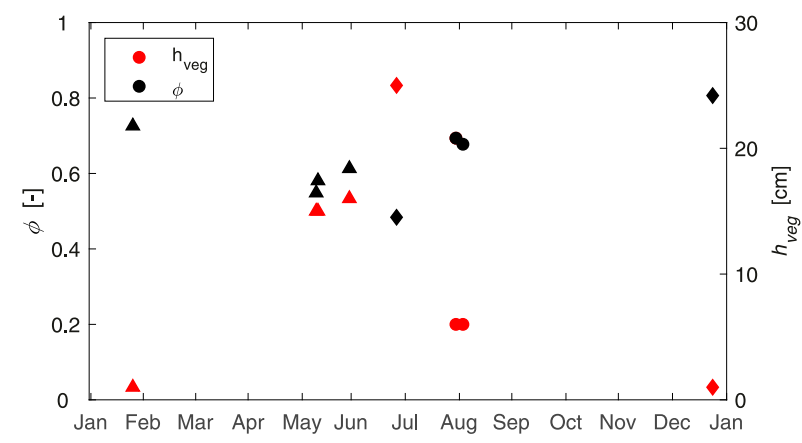

FIG. 2. The runoff coefficient $\phi$ of the rainfall simulator experiments and grass height $h_{\mathrm{veg}}$ during the observation period (2010 data in circles, 2011 data in diamonds, and 2012 data in triangles).

\section{c. The infiltration model}

We used a common infiltration model (Philip) and assumed that $k_{s}$ was the key parameter of the model.

\section{1) PHILIP MODEL}

The infiltration model proposed by Philip (1957) for estimating cumulative infiltration $F$ is

$$
F=\Sigma t^{1 / 2}+A t
$$

where $\Sigma$ is the sorptivity, which is a function of the soil suction potential, and $A$ is a soil parameter that is related to $k_{s}$ (e.g., Tindall and Kunkel 1999). The infiltration rate can be obtained by differentiating Eq. (1) to obtain

$$
f=\frac{1}{2} \Sigma t^{-1 / 2}+A
$$

Parameter $A$ was estimated using the Eagleson (1978) approximation (Wilson et al. 2014):

$$
A=\frac{1}{2} k_{s}\left[1+\left(\theta / \theta_{s}\right)^{2 b+3}\right]
$$

where $b$ is the soil water retention curve parameter (Clapp and Hornberger 1978). Parameter $\Sigma$ was estimated using the Sivapalan et al. (1987) approach as

$$
\begin{aligned}
\Sigma= & \left\{[ 2 k _ { s } ( \theta _ { s } - \theta ) ^ { 2 } ( - \frac { \psi _ { b } } { \theta _ { s } - \theta _ { r } } ) ] \left[\frac{1}{(2 b+3)+1 / 2 b}\right.\right. \\
& \left.\left.+\frac{\theta_{s}-\theta_{r}}{\theta_{s}-\theta}\right]\right\}^{1 / 2},
\end{aligned}
$$

where $\psi_{b}$ is the air entry suction head.

2) ESTIMATING THE $\boldsymbol{k}_{s}$ PARAMETER FOR THE INFILTRATION MODEL

Using the observations of discharge and soil moisture from each experiment, the parameters of the infiltration model were calibrated to minimize the errors between the modeled and observed discharges. Indeed, based on the difference between precipitation and modeled infiltration, we derived modeled surface runoff assuming negligible grass rainfall interception for high rainfall [in fact, given an estimated storage capacity of 0.2 LAI (in mm; Noilhan and Planton 1989), even using the maximum grass LAI of 2 (see Montaldo et al. 2008), rainfall interception reaches at most $0.4 \mathrm{~mm} \mathrm{~h}^{-1}$, which is negligible compared to $62 \mathrm{~mm} \mathrm{~h}^{-1}$ of rain]. As anticipated, we assumed that $k_{s}$, as the key parameter of the Philip model, was the only soil parameter that could change for each experiment and each model during calibration. Constant values of the other model parameters were calibrated for all experiments.

A multiobject calibration was performed using the Pareto ordering optimization method for minimizing RMSE between observed and modeled discharges and the ratio between modeled peak flow, $q_{p, m}$, and observed peak flow, $q_{p, o}$. The $\eta$ model efficiency of Nash and Suttcliffe (1970) was also used for evaluating model performance. The term $\eta$ is defined as

$$
\eta=1-\frac{\sum_{j=1}^{n_{t}}\left(q_{m, j}-q_{o, j}\right)^{2}}{\sum_{j=1}^{n_{t}}\left(q_{o, j}-\overline{q_{o}}\right)^{2}},
$$

where $n_{t}$ is the total number of time steps, $q_{o, j}$ and $q_{m, j}$ are the observed and modeled discharges at time step $j$, respectively, and $\overline{q_{o}}$ is the mean of the observed discharges.

\section{d. The ecohydrologic model}

As an ecohydrologic model we used the coupled vegetation dynamic model (VDM)-land surface model (LSM) of Montaldo et al. (2005, 2008), which predicts the dynamics of water and energy fluxes at the land surface in half-hour time steps. The model estimates surface temperature and moisture states through the force-restore method (Noilhan and Planton 1989; Montaldo and Albertson 2001). The root zone supplies the bare soil and vegetation with soil moisture for evapotranspiration and controls the infiltration and runoff mechanisms. The base of the root zone represents the lower boundary of the LSM, and evapotranspiration is estimated using the Penman-Monteith equation (e.g., Brutsaert 1982). In unsaturated soil, the Clapp and Hornberger (1978) relationships are used to describe the nonlinear dependencies of volumetric soil moisture and hydraulic conductivity on the matric potential. The infiltration model is based on the Philip infiltration Eqs. (1)-(4). VDM computes the change in 

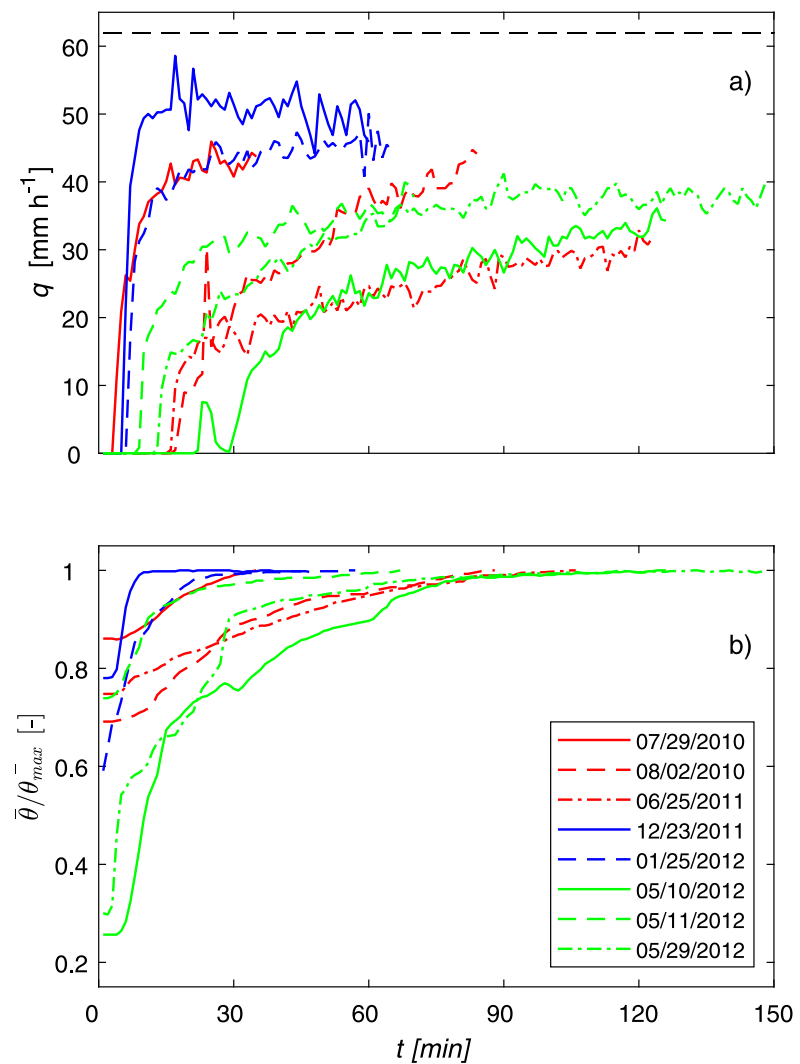

FIG. 3. Results of the rainfall simulator experiments: (a) observed time series of discharges $q$ (the horizontal dashed line is the constant rainfall rate of $62 \mathrm{~mm} \mathrm{~h}^{-1}$ ) and (b) the spatial mean field soil moisture $\bar{\theta}$ divided by its maximum value in each experiment over time.

biomass over time from the difference between the rate of biomass production (due to photosynthesis) and loss, such as occur through respiration and senescence (Montaldo et al. 2005). LAI values are estimated from the biomass through linear relationships, and they are then used in the LSM to compute rainfall interception, evapotranspiration, and the soil water content in the root zone. The model was tested at the Orroli site by Montaldo et al. (2008) using micrometeorological observations of a 10-m, eddy-covariance tower from 2003 to 2006 . That model used a calibrated and constant $k_{s}$ value of $5 \times 10^{-6} \mathrm{~m} \mathrm{~s}^{-1}$.

\section{Results}

\section{a. Results of the rainfall simulator experiments}

In all the rainfall simulator experiments, after some ponding time, observed discharges increased rapidly, reaching a constant maximum rate $\left(q_{p} ;\right.$ Fig. 3a) when soil moisture became saturated (Fig. $3 b$ ). Parameter $q_{p}$
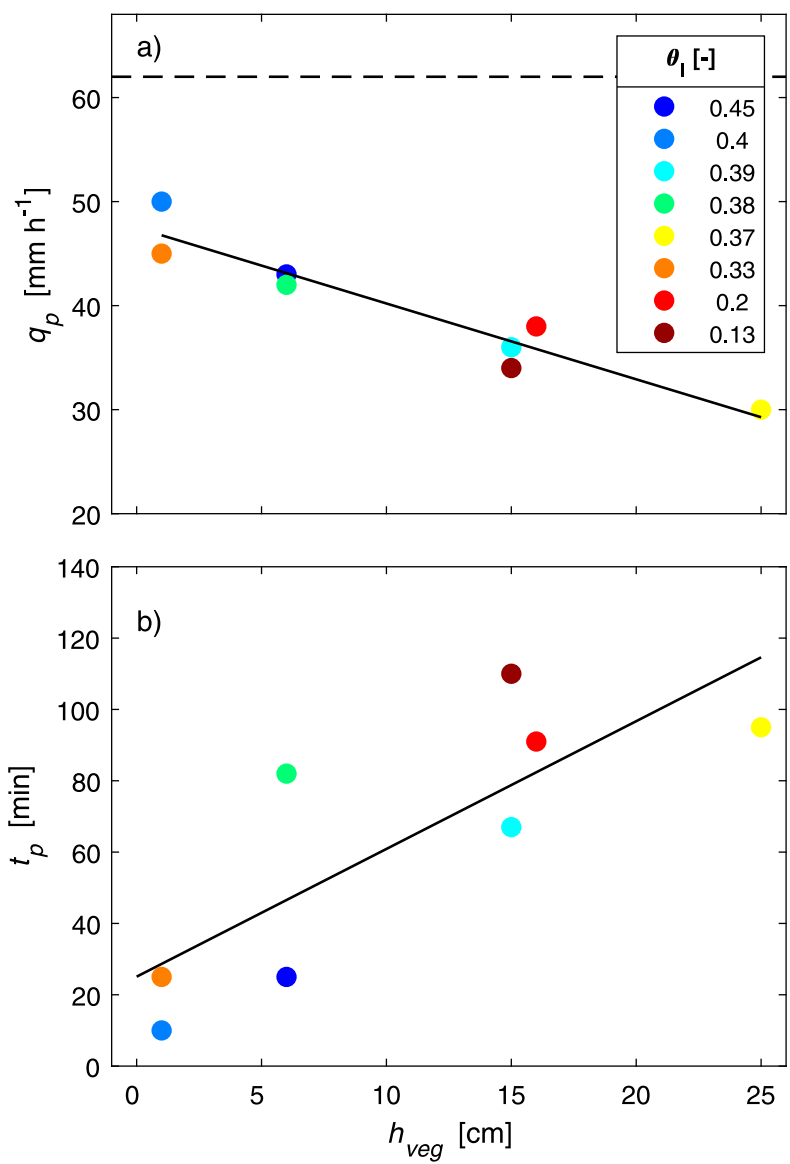

FIG. 4. Results of the rainfall simulator-based experiments: (a) peak runoff $q_{p}$ vs vegetation height $h_{\text {veg }}$ (the regression line in black has equation $q_{p}=-0.73 h_{\mathrm{veg}}+48 \mathrm{~mm} \mathrm{~h}^{-1}$, while the horizontal dashed line is constant rain of $62 \mathrm{~mm} \mathrm{~h}^{-1}$ ); (b) peak flow lag $t_{p}$ vs $h_{\mathrm{veg}}$ (the regression in black has equation $t_{p}=3.58 h_{\mathrm{veg}}+25.07 \mathrm{~min}$ ). The initial spatial soil moisture conditions $\overline{\theta_{i}}$ of the experiments are also indicated with colors (corresponding values in the legend).

ranged between 30 and $50 \mathrm{~mm} \mathrm{~h}^{-1}$ (Table 1 and Fig. 3a) and was reached at different times $\left(t_{p}\right)$ in the experiments (from 10 to $110 \mathrm{~min}$; Table 1 and Fig. 3a), suggesting that other factors, such as $\overline{\theta_{i}}$ or grass growth stages, influenced the surface runoff generation process.

Indeed, considering all experiments, $q_{p}$ was significantly and negatively correlated with $h_{\mathrm{veg}}\left(R^{2}=0.90\right.$, $p<0.01$; Fig. 4a) while not being significantly correlated with $\overline{\theta_{i}}(p>0.1)$. The time to peak flow was correlated positively with $h_{\mathrm{veg}}\left(R^{2}=0.58, p=0.01\right.$; Fig. $\left.4 \mathrm{~b}\right)$ and negatively with $\overline{\theta_{i}}\left(R^{2}=0.42, p=0.08\right)$. Although we estimated a general, positive correlation between $t_{p}$ and $h_{\text {veg }}$ (Fig. 4b), $t_{p}$ varied for similar $h_{\text {veg values due to the }}$ variability of $\overline{\theta_{i}}$, which instead did not impact the relationship of $q_{p}$ with $h_{\text {veg }}$ (Fig. 4a). Hence, we deduce that peak flow significantly decreased with grass growth, 
while the time to peak flow increased with grass growth and the decrease of $\overline{\theta_{i}}$ (Fig. 4).

Due to the strong negative correlation between $q_{p}$ and $h_{\mathrm{veg}}$ in the experiments, $\phi$ decreased seasonally with increasing grass height, as shown in Fig. 2, which patches together $\phi$ and $h_{\text {veg }}$ observations from 2010 to 2012 to capture their typical seasonal dynamics over a year. Indeed, during autumn and winter, the field was not densely vegetated $\left(h_{\mathrm{veg}} \approx 1 \mathrm{~cm}\right)$. Due to the low grass development at this time, $\phi$ reached a maximum value of 0.8 . During the vegetation growth season, by contrast, $\phi$ decreased to a minimum of 0.5 at the end of June, when $h_{\mathrm{veg}}$ reached its maximum value of $25 \mathrm{~cm}$ (Fig. 2). Parameters $\phi$ and $h_{\text {veg }}$ were also significantly and negatively correlated $\left(R^{2}=0.91, p<0.01\right)$ due to a negative correlation between $q_{p}$ and $h_{\mathrm{veg}}$ (correlation coefficient of -0.96).

\section{$b$. The $k_{s}$ estimates in the model}

We modeled rainfall-runoff transformations of each of the eight rainfall-simulator experiments using the Philip infiltration model (Fig. 5). Model calibrations allowed estimating $k_{s}$ for each experiment (Table 2). The other model parameters were calibrated and maintained identical across all experiments $\left(b=8, \theta_{s}=0.6\right.$, $\left.\psi_{b}=0.11 \mathrm{~m}\right)$. Discharges were well predicted for all the experiments (Fig. 5 and Table 2), with RMSE lower than $2.5 \mathrm{~mm} \mathrm{~h}^{-1}$, including a close match of modeled and observed peak flows (less than $10 \%$ differences between $q_{p, m}$ and $q_{p, o}$ ), and high $\eta$ (except for the 29 July 2010 experiment, which had, however, $q_{p, m} / q_{p, o}$ of 0.99 and low RMSE). We investigated the relationship of $k_{s}$ with $h_{\mathrm{veg}}$ in the experiments (Fig. 6). A significant increase of $k_{s}$ with $h_{\text {veg }}$ was estimated $\left(R^{2}=0.90\right.$ and $\left.p<0.01\right)$ (Fig. 6), with $k_{s} 3$ times larger (at $\sim 9 \times 10^{-6} \mathrm{~m} \mathrm{~s}^{-1}$ ) with the highest grass than with the lowest $h_{\mathrm{veg}}\left(\sim 3 \times 10^{-6} \mathrm{~m} \mathrm{~s}^{-1}\right.$; Fig. 6). We estimated a linear regression between $k_{s}$ and $h_{\text {veg }}$ (Fig. 6):

$$
k_{s}\left(h_{\mathrm{veg}}\right)=2.17 \times 10^{-7} h_{\mathrm{veg}}+3.35 \times 10^{-6} .
$$

This relationship may be used in infiltration models to model the seasonal variability of $k_{s}$ with grass growth. Note that using Eq. (6), the Philip model, still made accurate runoff predictions, with differences between $q_{p, m}$ and $q_{p, o}$ less than $12 \%$ (Table 3 ); this confirms the reliability of the approach.

\section{c. Impact of seasonal dynamics of grass on runoff model predictions}

We evaluated the relevance of using $k_{s}$ varying with grass growth in surface runoff model predictions by comparing model predictions using time-invariant $k_{s}$, as is common in hydrologic models, with those using $k_{s}$ varying with grass changes [i.e., using the proposed $k_{s}$ $\left(h_{\text {veg }}\right)$ relationship of Eq. (6)].

At the event time scale, for each experiment we first compared predicted $q_{p}$ using variable $k_{s}$ with $h_{\mathrm{veg}}\left[k_{s, v}\right.$, given by Eq. (6)], or $q_{p m, v}$, with predicted $q_{p}$ using timeinvariant $k_{s}\left(k_{s, c}\right.$, values in the range of $\left.3-9 \times 10^{-6} \mathrm{~m} \mathrm{~s}^{-1}\right)$, or $q_{p m, c}$ (Fig. 7). Using time-invariant $k_{s}$ in the Philip model overestimated $q_{p}$ (up to $65 \%$ ) for high $h_{\mathrm{veg}}$ when low $k_{s, c}$ values were used and underestimated $q_{p}$ (up to $43 \%$ ) for low $h_{\mathrm{veg}}$ when high $k_{s, c}$ values were used (Fig. 7). To better evaluate the results, we also plotted (Fig. 7) the linear regressions between $q_{p m, c}$ or $q_{p m, v}$ and $h_{\mathrm{veg}}$ for each value of $k_{s, c}$ (Table 4). Using the previously calibrated $k_{s, c}$ value $\left(=5 \times 10^{-6} \mathrm{~m} \mathrm{~s}^{-1}\right)$ by Montaldo et al. (2008), $q_{p}$ was underestimated (up to $15 \%$ ) for low $h_{\text {veg }}$ and overestimated (up to $40 \%$ ) for high $h_{\text {veg }}$, confirming the need to account for changes in $k_{s}$ with grass growth in the Philip model.

Then, we used the ecohydrologic model of Montaldo et al. (2008) to predict runoff, land surface fluxes, and $k_{s, v}$ at the plot scale for the 2003-14 period (model parameters are the same values as Table 1 of Montaldo et al. 2008). Indeed, the ecohydrologic model predicted daily LAI values, and then $h_{\mathrm{veg}}$ was estimated daily from LAI $\left(h_{\mathrm{veg}}=6.225 \mathrm{LAI}^{2}+7.572 \mathrm{LAI}\right.$ from field investigation); finally, $k_{s, v}$ was estimated using Eq. (6). Note that the changes of predicted $h_{\mathrm{veg}}$ resulted also in changes of roughness lengths for evapotranspiration estimates (Montaldo et al. 2005).

Predicted $k_{s, v}$ was predominantly lower (for $\sim 73 \%$ of the simulation period) than the previously calibrated $k_{s, c}$ of $5 \times 10^{-6} \mathrm{~m} \mathrm{~s}^{-1}$ (Fig. 8a). $k_{s, v}$ increased mainly during spring (with grass growth) and increased exceptionally so during spring $2004\left(k_{s, v}\right.$ reached $\left.8.4 \times 10^{-6} \mathrm{~m} \mathrm{~s}^{-1}\right)$ and spring $2014\left(k_{s, v}\right.$ reached $\left.8.1 \times 10^{-6} \mathrm{~m} \mathrm{~s}^{-1}\right)$, which were very wet; in spring 2004, LAI on site reached its maximum observed value of 2 (see Fig. 3 in Montaldo et al. 2008). We compared model predictions using $k_{s}$ varying with $h_{\mathrm{veg}}\left[k_{s, v}\right.$, Eq. (6)] with those using time-invariant $k_{s, c}$ of $5 \times 10^{-6} \mathrm{~m} \mathrm{~s}^{-1}, k_{s, c}^{*}$, as calibrated by Montaldo et al. (2008). The soil water dynamics was well predicted by the model for the long 2003-14 period (Fig. 8b). Model performance values for predicting soil moisture and evapotranspiration (ET) were similar using $k_{s, v}$ (RMSE of $\theta=0.06$, Fig. 8b; RMSE of ET $=0.80 \mathrm{~mm} \mathrm{day}^{-1}$ ) and $k_{s, c}^{*}$ (RMSE of $\theta=0.06$; RMSE of ET $=0.82 \mathrm{~mm} \mathrm{day}^{-1}$ ). In contrast, $q_{p}$ model predictions, $q_{p, m}$, were mainly underestimated when $k_{s, c}^{*}$ was used instead of $k_{\mathrm{s}, v}$ at the event time scale \{see Fig. 8c; $\left.\epsilon_{e}=\left[q_{p, m}\left(k_{s, c}^{*}\right)-q_{p, m}\left(k_{s, v}\right)\right] / q_{p, m}\left(k_{s, v}\right)\right\}$, with increasing underestimates as $\phi$ decreased, often reaching $100 \%$ underestimates for $\phi$ lower than 0.35 . The $q_{p, m}$ was overestimated when $k_{s, c}^{*}$ was used instead 

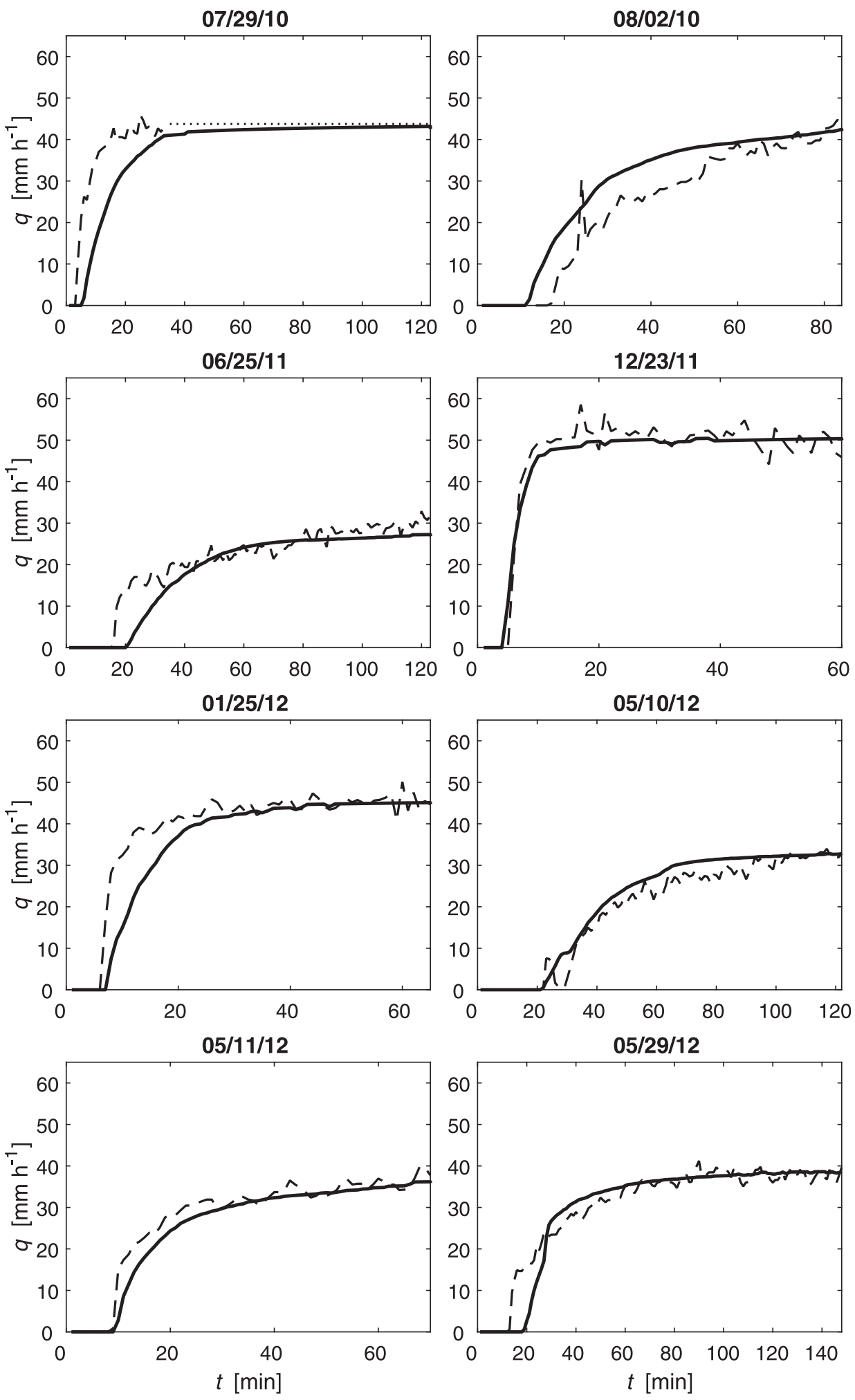

FIG. 5. The calibration of the Philip's model for discharge $q$ predictions of the eight rainfall simulator experiments (dashed line for observed values and solid line for predicted values; in the 29 Jul 2010 experiment, the dotted line for constant $q$ values was added for improving model calibration; $t$ is the time). 
TABLE 2. For each rainfall simulator experiment, $k_{\mathrm{s}}$ estimated using the Philip infiltration model, along with statistical indicators of fit for the discharge simulations (RMSE, the ratio between the modeled and observed peak flows $q_{p, m} / q_{p, o}$, and the Nash-Sutcliffe efficiency $\eta$ ).

\begin{tabular}{lcccc}
\hline \hline \multicolumn{1}{c}{ Date } & $k_{\mathrm{s}}\left(\mathrm{m} \mathrm{s}^{-1}\right)$ & $\mathrm{RMSE}\left(\mathrm{mm} \mathrm{h}^{-1}\right)$ & $q_{p, m} / q_{p, o}$ & $\eta$ \\
\hline 29 Jul 2010 & $4.3 \times 10^{-6}$ & 2.54 & 0.99 & 0.33 \\
2 Aug 2010 & $4.3 \times 10^{-6}$ & 2.48 & 0.96 & 0.85 \\
25 Jun 2011 & $9.0 \times 10^{-6}$ & 2.07 & 0.95 & 0.78 \\
23 Dec 2011 & $3.0 \times 10^{-6}$ & 1.80 & 1.10 & 0.95 \\
25 Jan 2012 & $4.7 \times 10^{-6}$ & 2.53 & 1.01 & 0.76 \\
10 May 2012 & $7.0 \times 10^{-6}$ & 1.67 & 0.97 & 0.95 \\
11 May 2012 & $7.0 \times 10^{-6}$ & 1.73 & 0.96 & 0.93 \\
29 May 2012 & $6.0 \times 10^{-6}$ & 1.97 & 0.97 & 0.89 \\
\hline
\end{tabular}

of $k_{s, v}$ only during end-spring events because $k_{s, v}$ was higher than $k_{s, c}^{*}$. Monthly runoff predictions $Q_{m}$ were also mainly underestimated using $k_{s, c}^{*}$ instead of $k_{s, v}$ $\left\{\right.$ Fig. $\left.7 \mathrm{~b} ; \epsilon_{m}=\left[Q_{m}\left(k_{s, c}^{*}\right)-Q_{m}\left(k_{s, v}\right)\right] / Q_{m}\left(k_{s, v}\right)\right\}$, with $\varepsilon_{m}$ values reaching a minimum value of -0.87 .

The estimate of $h_{\mathrm{veg}}$ is commonly affected by uncertainties (up to 20\%; Hopkinson et al. 2005) due to both its estimate from LAI and the LAI estimate itself from, for instance, remote sensing observations (Glenn et al. 2011). For evaluating the effect of these uncertainties in our analysis, we generated uncertainty in $h_{\mathrm{veg}}$ estimates intentionally, and predicted the impacts on $k_{s}$ and runoff. We altered randomly predicted original $h_{\text {veg }}$ time series up to $\pm 40 \%\left[\Delta h_{\text {veg }}\right.$; Fig. 9 ; note that $40 \%$ was twice the uncertainty of Hopkinson et al. (2005)]. Increasing $\Delta h_{\mathrm{veg}}$, both the mean and the variability range of $k_{s, v}$ increased (Fig. 9a). With $\Delta h_{\text {veg }}$ increased up to $20 \%$, mean $k_{s, v}$ increased up to $5 \%$ and SD increased up to $20 \%$; for $\Delta h_{\mathrm{veg}}=40 \%$, these increases of $k_{s, v}$ doubled (Fig. 9a). The changes of $h_{\text {veg }}$ lightly affected runoff predictions, so that, considering rainy events with $\phi$ larger than 0.1 , the impact on $q_{p, m}$ was almost negligible for positive $\Delta h_{\text {veg }}$, while $q_{p, m}$ could be slightly overestimated using $h_{\text {veg }}$ altered with negative $\Delta h_{\text {veg }}$ (up to $10 \%$ for $\Delta h_{\text {veg }}$ less than $20 \%$, Fig. $9 \mathrm{~b}$ ). Considering rainy events with $\phi$ larger than 0.4 , the effects on $q_{p, m}$ were further reduced becoming almost negligible for all the $\Delta h_{\text {veg }}$ range (Fig. 9b).

\section{Discussion and conclusions}

Corona et al. (2013) and Wilson et al. (2014) demonstrated that their large-area (approximately $16 \mathrm{~m}^{2}$ ) rainfall simulator-based systems accurately modeled actual rainfall fields. Using the rainfall simulator of Wilson et al. (2014), our eight plot-scale experiments (Table 1) allowed broad investigation of the influence of different initial conditions for soil moisture and

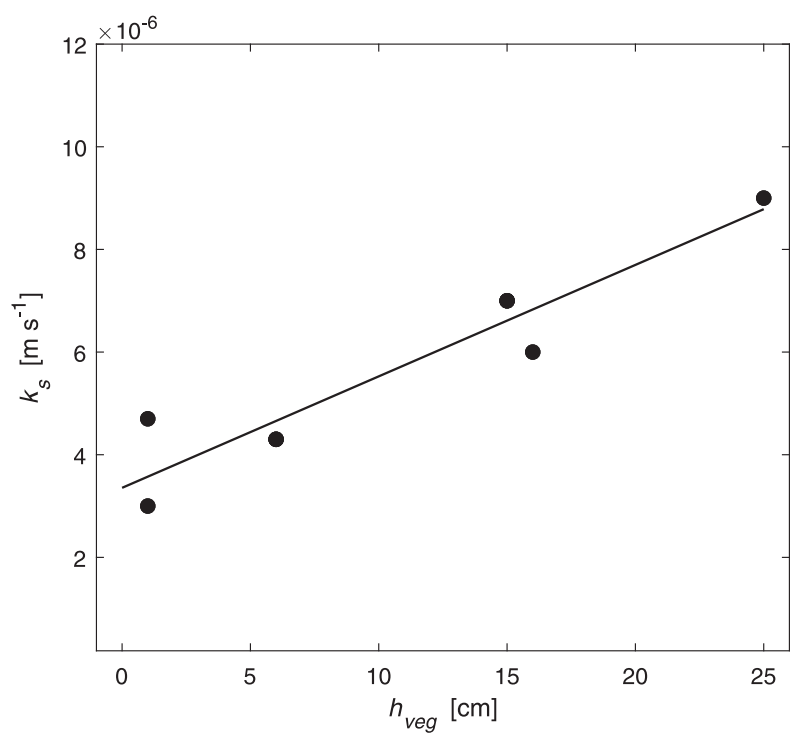

FIG. 6. Variability of the saturated hydraulic conductivity $k_{s}$ estimated using the Philip model, along with the height of vegetation $h_{\mathrm{veg}}$; the solid line is the linear regression in Eq. (6).

stages of grass growth on rainfall-runoff transformations. Surprisingly, typical characteristics of the hydrographs, $q_{p}$ and $t_{p}$, were conditioned mainly by $h_{\mathrm{veg}}$ (Fig. 3), while initial soil moisture conditions affected only $t_{p}$ to a lesser extent. Peak discharge is the key hydrograph characteristic, commonly used in designs for flood protection and hydrologic forecasting (e.g., Bennett and Mays 1985; Ponce 1989; Montaldo et al. 2004; Mediero et al. 2010). Although we were not investigating hydrologic processes at basin scale, our results showed that at plot scale the peak flow was significantly affected by grass growth, and this factor may potentially impact the flood hydrograph, especially for small basins with steep hillslopes, even if other basin-scale dependent factors may lower this effect. This effect is commonly neglected, however (e.g., Nouvellon et al. 2000; Arora 2003; Montaldo et al. 2005).

TABLE 3. For each rainfall simulator field experiment, statistical indicators of fit for discharge simulations (RMSE and the ratio between the modeled peak flow and the observed peak flow $\left.q_{p, m} / q_{p, o}\right)$ using the Philip model and $k_{s}$ varying with $h_{\mathrm{veg}}$ [Eq. (6)].

\begin{tabular}{lcc}
\hline \multicolumn{1}{c}{ Date } & $\operatorname{RMSE}\left(\mathrm{mm} \mathrm{h}^{-1}\right)$ & $q_{p, m} / q_{p, o}$ \\
\hline 29 Jun 2010 & 2.73 & 0.96 \\
2 Aug 2010 & 2.24 & 0.93 \\
25 Jun 2011 & 2.00 & 0.88 \\
23 Dec 2011 & 2.11 & 1.05 \\
25 Jan 2012 & 2.15 & 1.10 \\
10 May 2012 & 1.94 & 1.01 \\
11 May 2012 & 1.50 & 1.00 \\
29 May 2012 & 2.17 & 0.90 \\
\hline
\end{tabular}




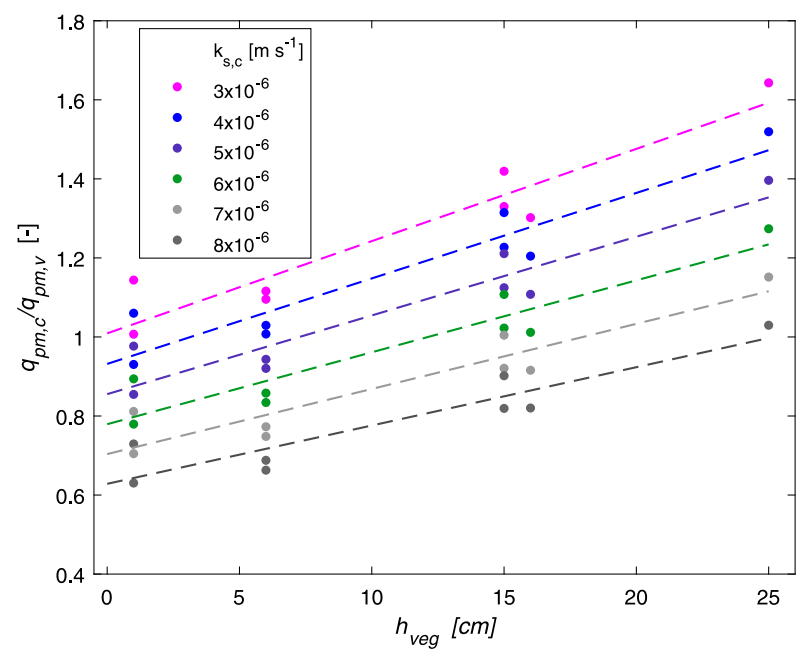

FIG. 7. Using the Philip model, the ratios between predicted $q_{p}$ using constant $k_{s}$ values $\left(q_{p m, c}\right.$; the legend shows the constant $k_{s, c}$ values) and predicted $q_{p}\left(q_{p m, v}\right)$ using $k_{s}$ varying with $h_{\text {veg }}$, as in Eq. (6), vs the height of vegetation $h_{\mathrm{veg}}$. Dashed lines are the linear regressions between $q_{p m, c} / q_{p m, v}$ and $h_{\mathrm{veg}}$ for each $k_{s, c}$ (equations and statistical indicators of fit are in Table 4).

Note that the investigated grass was uniform and densely covered, which may be a limitation relative to larger, more heterogeneous landscapes.

The rainfall simulator experiments quantified the effect of grass growth on the peak runoff coefficient for a fixed rainfall intensity, which decreased by about $40 \%$ when grass reached its maximum height (Fig. 4). We estimated a runoff decrease higher than did Gutierrez and Hernandez (1996), who estimated a $29 \%$ decrease in runoff for similar vegetation, but our experiments used a larger, more representative rainfall simulator, a higher rainfall intensity and a more homogenous and dense grass, which has been shown to affect runoff (Dunne et al. 1991, 2011). Root formation appeared to have an important role in decreasing surface runoff with growing vegetation, exerting compressive and shear stresses on the soil and enhancing soil permeability and infiltration capacity through the formation of macropores, which facilitated soil aeration and water infiltration (Angers and Caron 1998; Vergani and Graf 2016). The runoff coefficient was inversely and significantly related to the height of grass, with the peak runoff coefficient lowering as far as 0.5 when $h_{\text {veg }}$ reached its maximum value (Fig. 2). Low peak runoff coefficients were estimated during the period of maximum grass growth (in late spring), while high values of $\phi$ were estimated in winter (up to 0.84), when the grass height was still low and its influence on runoff generation was negligible.

This behavior suggests the impact of grass growth on infiltration should be carefully considered in hydrologic
TABLE 4. Regression coefficients for $q_{p m, c} / q_{p m, v}=a_{1} h_{\mathrm{veg}}+a_{2}$ (Fig. 7), and their $R^{2}$ and $p$ values.

\begin{tabular}{ccccc}
\hline \hline$k_{s, c}\left(\mathrm{~m} \mathrm{~s}^{-1}\right)$ & $a_{1}$ & $a_{2}$ & $R^{2}$ & $p$ \\
\hline $3 \times 10^{-6}$ & 0.023 & 1.009 & 0.95 & $<0.0001$ \\
$4 \times 10^{-6}$ & 0.022 & 0.932 & 0.95 & $<0.0001$ \\
$5 \times 10^{-6}$ & 0.020 & 0.855 & 0.94 & $<0.0001$ \\
$6 \times 10^{-6}$ & 0.018 & 0.779 & 0.94 & $<0.0001$ \\
$7 \times 10^{-6}$ & 0.016 & 0.628 & 0.93 & $<0.0001$ \\
$8 \times 10^{-6}$ & 0.015 & 0.491 & 0.93 & $<0.0001$ \\
$9 \times 10^{-6}$ & 0.015 & 0.558 & 0.87 & $<0.0001$ \\
\hline
\end{tabular}

models, which at present commonly maintain timeinvariant soil infiltration parameters (Bormann and Klaassen 2008).

Following the approach of Wilson et al. (2014), we used the results of rainfall simulator experiments to estimate $k_{s}$ with a common infiltration model. The Philip's model performed well, and we found a strong relationship between $k_{s}$ and $h_{\text {veg }}$, proposing a linear relationship between them in Eq. (6) to vary $k_{s}$ with grass growth (e.g., $h_{\text {veg }}$ ). The $k_{s}$ increased up to triple with $h_{\text {veg }}$ according to the Philip model (Fig. 6), consistent with the results of Bormann and Klaassen (2008) in two grass fields in North Germany and Gadi et al. (2017).

Ecohydrologic models already consider vegetation dynamics for predicting evapotranspiration and precipitation interception (e.g., Montaldo et al. 2005, 2008; Ivanov et al. 2008; Istanbulluoglu et al. 2012). Ecohydrologists should therefore also include the dynamic effects of vegetation on soil hydrological properties for modeling infiltration and runoff processes. Indeed, we demonstrated that at the plot spatial scale the effect of grass growth on $k_{s}$ is crucial for modeling runoff at both event and larger (monthly) time scales. Neglecting $k_{s}$ variability with grass growth can lead to underestimated surface runoff by up to $100 \%$ at event time scales and by up to $87 \%$ at monthly time scales in our Mediterranean case study (Fig. 8). Note that surface runoff was mainly underestimated due to the typical rainfall seasonality of the Mediterranean climate (Montaldo and Sarigu 2017; Corona et al. 2018), with main rain events in winter when vegetation height was low and $k_{s}$ was also low. We used as index for grass growth the height of vegetation $h_{\text {veg }}$ because it can be derived by remote sensing observations, through vegetation index as LAI (Pittman et al. 2015), which are more attractive for unmonitored areas and, in general, for model predictions in operational approaches. We recognized that the estimate of $h_{\mathrm{veg}}$, especially in unmonitored areas, can be affected by uncertainty (Glenn et al. 2011; Hopkinson et al. 2005), but we demonstrated that the uncertainty in $h_{\text {veg }}$ has a low effect on $k_{s}$ and a minimal effect on runoff 

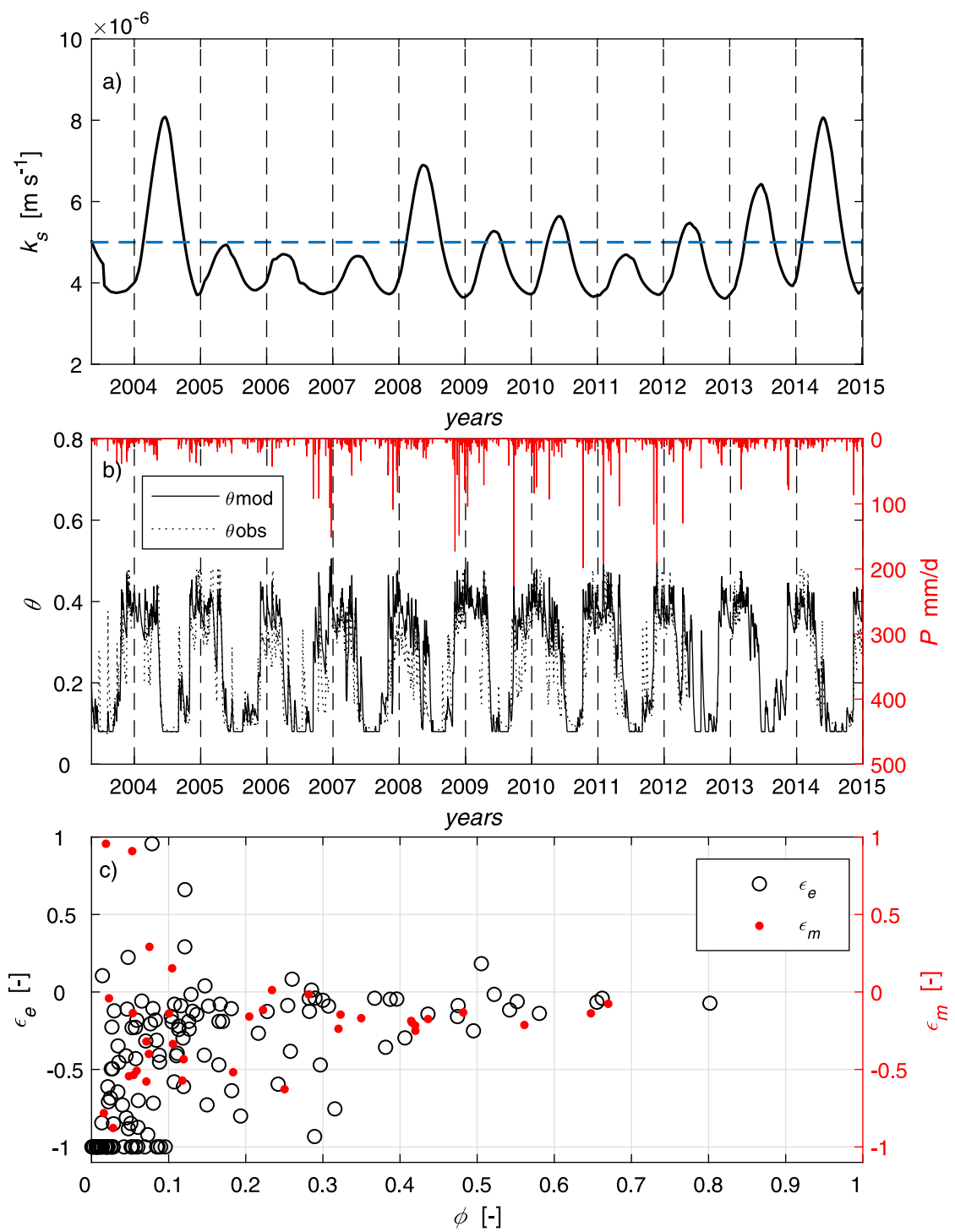

FIG. 8. Ecohydrological model results: (a) time series of the predicted variable $k_{s}$ (horizontal dashed blue line indicates the time-invariant $k_{s}$ that was calibrated by Montaldo et al. (2008); vertical dashed black lines indicate the start of the year); (b) time series of modeled (using the predicted variable $k_{s} ; \theta$ mod) and observed ( $\theta$ obs) soil moisture and daily precipitation $P$; (c) at the event time scale differences (black circles) between modeled peak flows using $k_{s}$ varying with $h_{\mathrm{veg}}$, or $q_{p, m}\left(k_{s, v}\right)$, and modeled peak flows using time-invariant $k_{s}$ of $5 \times 10^{-6} \mathrm{~m} \mathrm{~s}^{-1}$, or $q_{p, m}\left(k_{s, c}^{*}\right)$, expressed by $\epsilon_{e}=\left[q_{p, m}\left(k_{s, c}^{*}\right)-q_{p, m}\left(k_{s, v}\right)\right] / q_{p, m}\left(k_{s, v}\right)$, vs the event runoff coefficient $\phi$, and differences (red points) between modeled monthly runoff $Q_{m}$ using $k_{s, v}$ and $Q_{m}$ using $k_{s, c}^{*}$, expressed by $\epsilon_{m}=\left[Q_{m}\left(k_{s, c}^{*}\right)-Q_{m}\left(k_{s, v}\right)\right] / Q_{m}\left(k_{s, v}\right)$ vs the monthly runoff coefficient $\phi$.

predictions (Fig. 9), confirming the robustness of the proposed approach.

Hence, how grass growth influences soil infiltration parameters should be carefully considered for hydrological models to make appropriate runoff predictions. Doing so may potentially impact hydrological designs for both flood protection (event time scales) and waterresource management and planning, where the accurate prediction of monthly runoff is key (e.g., $\mathrm{Xu}$ and Singh 1998; Middelkoop et al. 2001). Montaldo et al. (2007) used the local-scale ecohydrologic model of Montaldo et al. (2005) in a spatially distributed hydrologic model at basin scale for flood predictions, noting the sensitivity of flood hydrograph to $k_{s}$, such as also shown by others (e.g., Anderton et al. 2002; Herbst et al. 2006). In this sense, future efforts will investigate the role of 

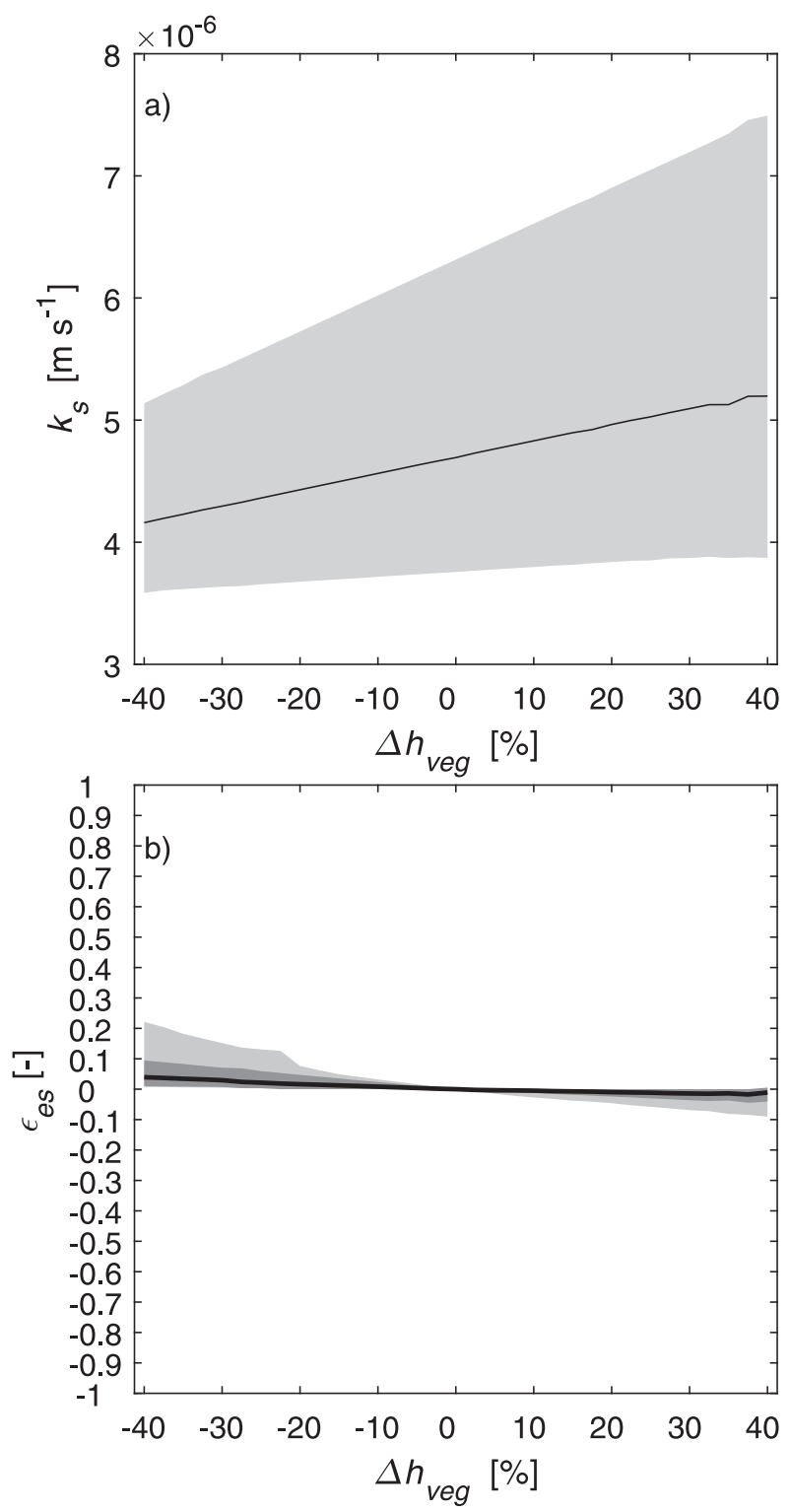

FIG. 9. Effects of changes of predicted original $h_{\mathrm{veg}}\left(\Delta h_{\mathrm{veg}}\right)$ time series (a) on predicted variable $k_{s}$ (shaded light gray area indicates the part of the ensemble between the 10th and the 90th percentiles and the black line the mean of those ensembles) and (b) on peak flow, expressed by $\epsilon_{e s}=\left\{\left(q_{p, m}\left[K_{s, v}\left(h_{\mathrm{veg}}+\Delta h_{\mathrm{veg}}\right)\right]-q_{p, m}\left[k_{s, v}\right.\right.\right.$ $\left.\left.\left(h_{\mathrm{veg}}\right)\right]\right\} / q_{p, m}\left[k_{s, v}\left(h_{\mathrm{veg}}\right)\right]$ (shaded light gray area indicates the part of the ensemble between the 10th and the 90th percentiles for events with $\phi>0.1$; shaded dark gray area indicates the part of the ensemble between the 10th and the 90th percentiles for events with $\phi>0.4$, and the black line the mean of those ensembles).

vegetation growth on runoff at basin scale, also investigating the effects on hydraulic roughness. Finally, we recognized that the number of rainfall experiments was low and that only one site was investigated, so that further experiments need more sites with different physiographic and climate conditions.
Acknowledgments. This work was supported by the Ministry of Education, University and Research (MIUR) through the SWATCH European project of the PRIMA MED program, the ALTOS European project of the PRIMA MED program, the FLUXMED European project of the WATER JPI program, and Regione Sardegna through the LR 19/2006. We thank Thomas Dunne and two anonymous reviewers for their useful comments and suggestions.

\section{REFERENCES}

Albertson, J. D., and G. Kiely, 2001: On the structure of soil moisture time series in the context of land surface models. J. Hydrol., 243, 101-119, https://doi.org/10.1016/S00221694(00)00405-4.

Anderton, S., J. Latron, and F. Gallart, 2002: Sensitivity analysis and multi-response, multi-criteria evaluation of a physically based distributed model. Hydrol. Processes, 16, 333-353, https://doi.org/10.1002/hyp.336.

Angers, D. A., and J. Caron, 1998: Plant-induced changes in soil structure: Processes and feedbacks. Biogeochemistry, 42, 55-72, https://doi.org/10.1023/A:1005944025343.

Arora, V. K., 2003: Simulating energy and carbon fluxes over winter wheat using coupled land surface and terrestrial ecosystem models. Agric. For. Meteor., 118, 21-47, https://doi.org/ 10.1016/S0168-1923(03)00073-X.

Bennett, M. S., and L. W. Mays, 1985: Optimal design of detention and drainage channel systems. J. Water Resour. Plann. Manage., 111, 19446, https://doi.org/10.1061/(ASCE)0733-9496(1985)111: 1(99).

Bormann, H., and K. Klaassen, 2008: Seasonal and land use dependent variability of soil hydraulic and soil hydrological properties of two Northern German soils. Geoderma, $\mathbf{1 4 5}$, 295-302, https://doi.org/10.1016/j.geoderma.2008.03.017.

Brutsaert, W., 1982: Evaporation into the Atmosphere. Springer, $302 \mathrm{pp}$.

Burgy, R. H., and R. Pomeroy, 1958: Interception losses in grassy vegetation. Trans. Amer. Geophys. Union, 39, 1095-1100, https://doi.org/10.1029/TR039I006P01095.

Cerdà, A., 1996: Seasonal variability of infiltration rates under contrasting slope conditions in southeast Spain. Geoderma, 69 , 217-232, https://doi.org/10.1016/0016-7061(95)00062-3.

Chow, T. L., 1976: A low-cost tipping bucket flowmeter for overland flow and subsurface stormflow studies. Can. J. Soil Sci., 56, 197-202, https://doi.org/10.4141/cjss76-028.

Clapp, R. B., and G. M. Hornberger, 1978: Empirical equations for some soil hydraulic properties. Water Resour. Res., 14, 601-604, https://doi.org/10.1029/WR014i004p00601.

Corona, R., T. Wilson, L. P. D’Adderio, F. Porcu, N. Montaldo, and J. Albertson, 2013: On the estimation of surface runoff through a new plot scale rainfall simulator in Sardinia, Italy. Procedia Environ. Sci., 19, 875-884, https://doi.org/10.1016/ j.proenv.2013.06.097.

_ N. Montaldo, and J. D. Albertson, 2018: On the role of NAODriveniInterannual variability in rainfall seasonality on water resources and hydrologic design in a typical mediterranean basin. J. Hydrometeor., 19, 485-498, https://doi.org/10.1175/ JHM-D-17-0078.1.

Crouse, R. P., E. S. Corbett, E.S., and D. W. Seegrist, 1966: Methods of measuring and analyzing rainfall interception by 
grass. Int. Assoc. Sci. Hydrol. Bull., 11, 110-120, https:// doi.org/10.1080/02626666609493463.

Dadkhah, M., and G. F. Gifford, 1980: Influence of vegetation, rock cover, and trampling on infiltration rates and sediment production. Water Resour. Bull., 16, 979-986, https://doi.org/ 10.1111/j.1752-1688.1980.TB02537.X.

Dunne, T., W. H. Zhang, and B. F. Aubry, 1991: Effects of rainfall, vegetation, and microtopography on infiltration and runoff. Water Resour. Res., 27, 2271-2285, https://doi.org/10.1029/91WR01585.

- D. Western, and W. E. Dietrich, 2011: Effects of cattle trampling on vegetation, infiltration, and erosion in a tropical rangeland. J. Arid Environ., 75, 58-69, https://doi.org/10.1016/ j.jaridenv.2010.09.001.

Eagleson, P. S., 1978: Climate, soil, and vegetation: 1. Introduction to water balance dynamics. Water Resour. Res., 14, 705-712, https://doi.org/10.1029/WR014I005P00705.

Fatichi, S., V. Y. Ivanov, and E. Caporali, 2012: A mechanistic ecohydrological model to investigate complex interactions in cold and warm water-controlled environments: 2. Spatiotemporal analyses. J. Adv. Model. Earth Syst., 4, M05002, https://doi.org/ 10.1029/2011MS000087.

Foley, J. A., and Coauthors, 2011: Solutions for a cultivated planet. Nature, 478, 337-342, https://doi.org/10.1038/nature10452.

Foster, I. D. L., M. A. Fullen, R. T. Brandsma, and A. S. Chapman, 2000: Drip-screen rainfall simulators for hydro- and pedogeomorphological research: The coventry experience. Earth Surf. Processes Landforms, 25, 691-707, https://doi.org/10.1002/ 1096-9837(200007)25:7<691::AID-ESP125>3.0.CO;2-4.

Gadi, V. K., Y.-R. Tang, A. Das, C. Monga, A. Garg, C. Berretta, and L. Sahoo, 2017: Spatial and temporal variation of hydraulic conductivity and vegetation growth in green infrastructures using infiltrometer and visual technique. Catena, 155, 20-29, https://doi.org/10.1016/j.catena.2017.02.024.

Gao, S., Z. Niu, N. Huang, and X. H. Hou, 2013: Estimating the Leaf Area Index, height and biomass of maize using HJ-1 and RADARSAT-2. Int. J. Appl. Earth Obs. Geoinf., 24, 1-8, https://doi.org/10.1016/j.jag.2013.02.002.

Glenn, N. F., L. P. Spaete, T. T. Sankey, D. R. Derryberry, S. P. Hardegree, and J. J. Mitchell, 2011: Errors in LiDAR-derived shrub height and crown area on sloped terrain. J. Arid Environ., 75, 377-382, https://doi.org/10.1016/j.jaridenv.2010.11.005.

Green, W. H., and C. A. Ampt, 1911: Studies on soil physics: Part II - The permeability of an ideal soil to air and water. J. Agric. Sci., 5, 1-24, https://doi.org/10.1017/S0021859600001751.

Gutierrez, J., and I. I. Hernandez, 1996: Runoff and interrill erosion as affected by grass cover in a semi-arid rangeland of northern Mexico. J. Arid Environ., 34, 287-295, https:// doi.org/10.1006/jare.1996.0110.

Herbst, M., B. Diekkrüger, and J. Vanderborght, 2006: Numerical experiments on the sensitivity of runoff generation to the spatial variation of soil hydraulic properties. J. Hydrol., 326, 43-58, https://doi.org/10.1016/j.jhydrol.2005.10.036.

Hopkinson, C., L. E. Chasmer, G. Sass, I. F. Creed, M. Sitar, W. Kalbfleisch, and P. Treitz, 2005: Vegetation class dependent errors in lidar ground elevation and canopy height estimates in a boreal wetland environment. Can. J. Remote Sens., 31, 191206, https://doi.org/10.5589/m05-007.

Horton, R. E., 1933: The role of infiltration in the hydrological cycle. Trans. Amer. Geophys. Union, 14, 446-460, https:// doi.org/10.1029/TR014i001p00446.

_ 1939: Analysis of runoff-plat experiment with varying infiltration-capacity. Trans. Amer. Geophys. Union, 20, 693-711, https://doi.org/10.1029/TR020i004p00693.
Hu, W., M. A. Shao, and B. C. Si, 2012: Seasonal changes in surface bulk density and saturated hydraulic conductivity of natural landscapes. Eur. J. Soil Sci., 63, 820-830, https://doi.org/ 10.1111/j.1365-2389.2012.01479.x.

Istanbulluoglu, E., T. J. Wang, and D. A. Wedin, 2012: Evaluation of ecohydrologic model parsimony at local and regional scales in a semiarid grassland ecosystem. Ecohydrology, 5, 121-142, https://doi.org/10.1002/eco.211.

Ivanov, V. Y., R. L. Bras, and E. R. Vivoni, 2008: Vegetationhydrology dynamics in complex terrain of semiarid areas: 2 . Energy-water controls of vegetation spatiotemporal dynamics and topographic niches of favorability. Water Resour. Res., 44, W03430, https://doi.org/10.1029/2006WR005595.

Kabat, P., R. W. A. Hutjes, and R. A. Feddes, 1997: The scaling characteristics of soil parameters: From plot scale heterogeneity to subgrid parameterization. J. Hydrol., 190, 363-396, https://doi.org/10.1016/S0022-1694(96)03134-4.

Kato, H., Y. Onda, Y. Tanaka, and M. Asano, 2009: Field measurement of infiltration rate using an oscillating nozzle rainfall simulator in the cold, semiarid grassland of Mongolia. Catena, 76, 173-181, https://doi.org/10.1016/j.catena.2008.11.003.

Leitinger, G., E. Tasser, C. Newesely, N. Obojes, and U. Tappeiner, 2010: Seasonal dynamics of surface runoff in mountain grassland ecosystems differing in land use. J. Hydrol., 385, 95-104, https://doi.org/10.1016/j.jhydrol.2010.02.006.

Mayerhofer, C., G. Meissl, K. Klebinder, B. Kohl, and G. Markart, 2017: Comparison of the results of a small-plot and a large-plot rainfall simulator - Effects of land use and land cover on surface runoff in Alpine catchments. Catena, 156, 184-196, https://doi.org/10.1016/j.catena.2017.04.009.

McMillan, W. D., and R. H. Burgy, 1960: Interception loss from grass. J. Geophys. Res., 65, 2389-2394, https://doi.org/10.1029/ JZ065I008P02389.

Mediero, L., A. Jimenez-Alvarez, and L. Garrote, 2010: Design flood hydrographs from the relationship between flood peak and volume. Hydrol. Earth Syst. Sci., 14, 2495-2505, https:// doi.org/10.5194/hess-14-2495-2010.

Middelkoop, H., and Coauthors, 2001: Impact of climate change on hydrological regimes and water resources management in the Rhine basin. Climatic Change, 49, 105-128, https://doi.org/ 10.1023/A:1010784727448.

Montaldo, N., and J. D. Albertson, 2001: On the use of the force-restore SVAT model formulation for stratified soils. J. Hydrometeor., 2, 571-578, https://doi.org/10.1175/15257541(2001)002<0571:OTUOTF $>2.0$.CO;2.

, and A. Sarigu, 2017: Potential links between the North Atlantic Oscillation and decreasing precipitation and runoff on a Mediterranean area. J. Hydrol., 553, 419-437, https:// doi.org/10.1016/j.jhydrol.2017.08.018.

, V. Toninelli, J. D. Albertson, M. Mancini, and P. A. Troch, 2003: The effect of background hydrometeorological conditions on the sensitivity of evapotranspiration to model parameters: Aanalysis with measurements from an Italian alpine catchment. Hydrol. Earth Syst. Sci., 7, 848-861, https://doi.org/ 10.5194/hess-7-848-2003.

— - M. Mancini, and R. Rosso, 2004: Flood hydrograph attenuation induced by a reservoir system: Analysis with a distributed rainfall-runoff model. Hydrol. Processes, 18, 545-563, https://doi.org/10.1002/hyp.1337.

, R. Rondena, J. D. Albertson, and M. Mancini, 2005: Parsimonious modeling of vegetation dynamics for ecohydrologic studies of water-limited ecosystems. Water Resour. Res., 41, W10416, https://doi.org/10.1029/2005WR004094. 
G. Ravazzani, and M. Mancini, 2007: On the prediction of the TOce alpine basin floods with distributed hydrologic models. Hydrol. Processes, 21, 608-621, https://doi.org/ 10.1002/hyp.6260.

_ J. D. Albertson, and M. Mancini, 2008: Vegetation dynamics and soil water balance in a water-limited Mediterranean ecosystem on Sardinia, Italy. Hydrol. Earth Syst. Sci., 12, 12571271, https://doi.org/10.5194/hess-12-1257-2008.

Nash, J., and J. Suttcliffe, 1970: River flow forecasting through conceptual models Part I - A discussion of principles. J. Hydrol., 10, 282-290, https://doi.org/10.1016/0022-1694(70) 90255-6.

Noilhan, J., and S. Planton, 1989: A simple parameterization of land surface processes for meteorological models. Mon. Wea. Rev., 117, 536-549, https://doi.org/10.1175/1520-0493(1989) $117<0536$ :ASPOLS $>2.0$.CO;2.

Nouvellon, Y., S. Rambal, D. Lo Seen, M. S. Moran, J. P. Lhomme, A. Bégué, A. G. Chehbouni, and Y. Kerr, 2000: Modelling of daily fluxes of water and carbon from shortgrass steppes. Agric. For. Meteor., 100, 137-153, https://doi.org/10.1016/ S0168-1923(99)00140-9.

Obermeier, W. A., and Coauthors, 2016: Reduced $\mathrm{CO}_{2}$ fertilization effect in temperate $\mathrm{C} 3$ grasslands under more extreme weather conditions. Nat. Climate Change, 7, 137-141, https://doi.org/ 10.1038/nclimate3191.

Philip, J. R., 1957: The theory of infiltration: 1 . The infiltration equation and its solution. Soil Sci., 83, 345-358, https://doi.org/ 10.1097/00010694-195705000-00002.

Pittman, J. J., D. B. Arnali, S. M. Interrante, C. A. Moffet, and T. J. Butler, 2015: Estimation of biomass and canopy height in bermudagrass, Alfalfa, and wheat using ultrasonic, laser, and spectral sensors. Sensors, 15, 2920-2943, https://doi.org/10.3390/ s150202920.

Podwojewski, P., J. L. Janeau, S. Grellier, C. Valentin, S. Lorentzb, and V. Chaplota, 2011: Influence of grass soil cover on water runoff and soil detachment under rainfall simulation in a subhumid South African degraded rangeland. Earth Surf. Processes Landforms, 36, 911-922, https://doi.org/10.1002/esp.2121.
Ponce, V. M., 1989: Engineering Hydrology. Prentice Hall, 640 pp. Rulli, M. C., S. Bozzi, M. Spada, D. Bocchiola, and R. Rosso, 2006: Rainfall simulations on a fire disturbed mediterranean area. J. Hydrol., 327, 323-338, https://doi.org/10.1016/ j.jhydrol.2005.11.037.

Schindler Wildhaber, Y., D. Bänninger, K. Burri, and Ch. Alewell, 2012: Evaluation and application of a portable rainfall simulator on subalpine grassland. Catena, 91, 56-62, https://doi.org/ 10.1016/j.catena.2011.03.004.

Sharpley, A., and P. Kleinman, 2003: Effect of rainfall simulator and plot scale on overland flow and phosphorus transport. J. Environ. Qual., 32, 2172-2179, https://doi.org/10.2134/ jeq2003.2172.

Sivapalan, M., K. Beven, and E. F. Wood, 1987: On hydrologic similarity: 2. A scaled model of storm runoff production. Water Resour. Res., 23, 2266-2278, https://doi.org/10.1029/ WR023i012p02266.

Tindall, J. A., and J. R. Kunkel, 1999: Unsaturated Zone Hydrology for Scientists and Engineers. Pearson Education, 624 pp.

Vergani, C., and F. Graf, 2016: Soil permeability, aggregate stability and root growth: A pot experiment from a soil bioengineering perspective. Ecohydrology, 9, 830-842, https:// doi.org/10.1002/eco.1686.

Volaire, F., and M. Norton, 2006: Summer dormancy in perennial temperate grasses. Ann. Bot., 98, 927-933, https://doi.org/ 10.1093/aob/mcl195.

Wilson, T. G., C. Cortis, N. Montaldo, and J. D. Albertson, 2014: Development and testing of a large, transportable rainfall simulator for plot-scale runoff and parameter estimation. Hydrol. Earth Syst. Sci., 18, 4169-4183, https://doi.org/10.5194/ hess-18-4169-2014.

Xu, C.-Y., and V. P. Singh, 1998: A review on monthly water balance models for water resources investigations. Water Resour. Manage., 12, 20-50, https://doi.org/10.1023/A:1007916816469.

Yuan, Y. W., X. S. Wang, F. Yin, and J. Y. Zhan, 2013: Examination of the quantitative relationship between vegetation canopy height and LAI. Adv. Meteor., 2013, 1-6, https:// doi.org/10.1155/2013/964323. 